\title{
SITUATIONAL EFFICIENCY PARAMETERS OF SUCCESSFUL AND UNSUCCESSFUL TOP MALE BASKETBALL TEAMS IN THE OLYMPIC TOURNAMENT GAMES IN LONDON 2012
}

\author{
Dragan Milanović, Lovro Štefan, Dario Škegro \\ University of Zagreb, Zagreb, Croatia
}

\begin{abstract}
Background. The purpose of this study was to determine differences in situational efficiency parameters that differentiate male basketball teams according to outcome. Sample of entities consisted of 38 games played in the Olympic Games in London 2012.

Methods. Situational efficiency variables that affected the final outcome were comprised of 13 parameters. Differences between successful and unsuccessful teams were obtained using Student's t-test. Also, overall differences between teams were analysed applying multivariate analysis of variance (MANOVA) and discriminant analysis with standardized canonical coefficients (SCC). Significant value was set up at $p \leq .05$.

Results. Results showed overall statistical differences in situational parameters between teams $(p<.001)$. Also, discriminant function showed that situation parameters 2 pts-fail $(F$-value $-14.82, \mathrm{SCC}=-0.967, p<.001), 3$ pts-fail $(F$-value $=5.57, \mathrm{SCC}=-0.403 ; p<.05)$, offensive rebounds $(\mathrm{F}$-value $-16.38, \mathrm{SCC}=0.943, p<.001)$, defensive rebounds $(F$-value $=6.66, \mathrm{SCC}=0.822, p<.05)$, turnovers $(F$-value $=14.03, \mathrm{SCC}=-0.608, p<.001)$ and steals $(F$-value $=4.78, \mathrm{SCC}=0.425, p<.05)$ differentiated most of the teams according to outcome.

Conclusion. On the basis of the obtained results we suggest that winning teams had technical-tactical parameters on higher level due to better timing of sports fitness with adequate resting periods and type of training process.
\end{abstract}

Keywords: team sport, notational analysis, final outcome.

\section{INTRODUCTION}

$\mathrm{B}$ asketball represents one of the most dynamic sports in the world (Pojskić, Šeparović, \& Užičanin, 2009). Within the game, player's quality, cooperation between the players, tactics and overall teamwork primary determine the team's efficiency and competitive success (Trninić, Dizdar, \& Dežman, 2000). Also, the whole game represents a furnished sequence of tasks which each player needs to get done according to the playing position and team role. The activity of individual player in basketball game started to get measureable through situational efficiency with standardised and non-standardised indicators in basketball game (Trninić, Milanović, \& Dizdar, 1997). International Basketball Federation (FIBA) standardizes thirteen indicators of situational efficiency that are followed during each game (Sindik \& Vidak, 2010). That is why situational parameters contribute the most in basketball game.

Situational parameters become one of the most important and objective factors determining overall efficiency in the game, especially in team sports. For example, in rugby, Hunter and O'Donoghue (2001) compared performance of successful and unsuccessful teams in World Cup 1999. Their study found statistical differences in two of eleven analysed variables in favour of successful teams (Hunter \& O'Donoghue, 2001). Also, Gruić, Vuleta, and Milanović (2006) analysed performance indicators of men's handball teams in 
World Handball Championship in Portugal 2003. They reported that the contribution of the predictor variables to the final successfulness criterion was statistically significant. The partial effects of regression analyses confirmed the importance of the situational efficiency of backcourt attacking players in the generation of final outcomes of handball matches. More precisely, missed shots from the field, along with fast break shots scored mostly influenced the final score.

In basketball, according to Dezman, Erculj and Vuckovic (2002), the process of winning depends on creating a strong team, which is defined by individual quality of each player. The study of game performance as a function of the differences in the final score of the game is becoming an important variable to consider (Garcia, Ibáñez, De Santos, Leite, \& Sampaio, 2013).

Therefore, it is not uprising that most of the studies tried to determine which situational efficiency parameters mostly differentiated successful and unsuccessful male basketball teams (Ibanez et al., 2008; Gomez, Lorenzo, Ortega, Sampaio, \& Ibáñez, 2009; Gomez, Lorenzo, Sampaio, Ibáñez, \& Ortega, 2008; Trninić, Dizdar, $\&$ Lukšić, 2002). To be more precise, Gomez et al. (2008) reported that 2 pts-made, defensive rebounds and assists represented parameters that differentiated successful teams from unsuccessful ones. Also, other studies showed that defensive rebounds differed the most winning and defeated teams (Akers, Wolff, \& Buttress, 1991; Trninić et al., 2002). Melnick (2001) tried to find connection between assists and final outcome of the game. The study conducted by Montgomery et al. (2008) reported that several consecutive games (3-day tournament) decreased physical capacities (jump power, agility and speed), possibly due to fatigue accumulated from successive games (Gabbett, 2008; Royal et al., 2006). Sampaio and Janeira (2003) reported that defeated teams performed worse in every observed parameter. Trninić et al. (2002) found that defensive and offensive rebounds along with shooting variables discriminated successful from unsuccessful teams the most. On a sample of 25 games of basketball league 1973/1974, Trninić (1975) examined the relationship between frequencies of caught balls in the phase of attack and defence with the final score of the game. The author determined real, but not high correlation between caught balls in the phase of defence and attack $(r=.46)$, along with low correlation between the same variables and the final score of the game $(r=.22)$ and between caught balls and number of baskets of the successful teams $(r=.25)$. Moreover, on a sample of 26 games of Yugoslavian Basketball Championship, Milanović (1978) established a significant impact of 4 situational variables of scoring the basket from different distances and 11 situational variables of scoring the basket different ways on the final score in basketball game. The author concluded that the final result mostly depended on shooting accuracy from different distances, along with the fact that successful teams determined scoring the basket from the distance and under the basket efficiency. Swalgin (1994) was examining players from Men's Division College for 3 years and established the situational efficiency variable norms between different playing positions and the time spent in the game. Based on that, the author created a computer programme for evaluating the player's efficiency on the court. Pojskić et al. (2009) conducted a study on 37 matches analysing 22 variables of standard and derived statistical indicators. The authors revealed that assists, $\%$ of 2 points, 2 points-made, defensive rebounds and bench points statistically significantly differed successful from those in unsuccessful teams. Nevertheless, the lack of studies conducted on male basketball teams playing in the Olympic Games represents a very important factor for better understanding the main differences between indicators which discriminate teams the most.

So, the aim of the present study was to determine which situational efficiency parameters mostly differentiated successful and unsuccessful teams playing in the Olympic Games in London 2012.

\section{METHODS}

Subjects. The study was conducted on the sample of 12 basketball teams (38 games, 76 opponents) playing in the Olympic Games in London 2012. The teams were divided into group A (15 games), group B (15 games), teams which got into the quarter-finals (4 games), teams which got into the semi-finals (2 games), finals (1 game) and 1 game for the third place.

Variables. The variables which represented situational efficiency comprised 13 standard indicators in basketball game proven by FIBA. All results were downloaded from the official FIBA website.

Variables for 2 points represent primary situational indicators for overall efficiency in the game. Those efficiencies ranged from 55 to $60 \%$ 
from the total of scored points in a basketball game. One of the most important principles of an organized (transitional and set) attack represents a selective shot. Due to that, organisation of the game must contain ball control and movement line, which allows the release of a large number of players for an "opened shot on a different playing position (Trninić, 1996).

Variables for 3 points represent great strategic importance because they make around $25 \%$ of total scored points in basketball games and around 36\% from the total of thrown balls. Because of that, requirements increase in the phase of defence for pressure in the front line of defence, but defence spreads. It means that opponent players have much more space for attack. Knight and Newell (1986) suggested that total shot percentage should not be lower than $52 \%$.

Free throws are defined as indefensible ball throws in the basket made as the result of punishing the opponent's team for a personal foul made. Between 15 and $30 \%$ of the total scored points during the game can be attributed to free throws.

Defensive rebounds represent the number of caught rejected balls in the phase of transitional or set defence. Trninić et al. (1997) showed that defensive rebounds were more significant indicators of situational efficiency than offensive rebounds $(\mathrm{RO}=0.57)$. According to Trninić (1996), defensive rebounds account for about $66 \%$ of total rebounds. Based on the fact that the transition from the phase of defence to the phase of attack starts when the player comes in possession of the ball, it is necessary to point out that defensive rebounds are important component for overall efficiency in the game.

Offensive rebounds represent the number of caught rejected balls in the phase of transitional or set offense. According to Knight and Newell (1986), the number of caught balls in the phase of defence and attack must be over $58 \%$ of the overall rebounds. Well-prepared and organized attack will cover offensive rebounds and keep defensive balance. It decreases psychological pressure on the shooter and simultaneously increases realization in attack.

Assists, according to Trninić (1996), are factors that produce "easy shots". Also, assists, percentage of free throws, offensive and defensive rebounds make very important components that discriminate successful from unsuccessful teams. Greater number of assists and caught balls generate with greater shoot efficiency, producing greater number of successful throws for 2 points and lower unsuccessful throws for 2 points.
Personal fouls represent illicit and irregular physical touch with the opponent, no matter if the ball is in the game or out.

Turnovers represent lost ball during the basketball game. In basics, minimal number of lost balls (around 6) points high level of individual and team game, along with high level of sports form of individuals and teams. Losing the ball in the phase of transitional and set attack was caused with aggressive defence and the level of ball control of the team who is in the phase of attack.

Steals represent successful and unsuccessful throws of the ball into the basket because higher numbers of stolen balls create assumptions for higher numbers of shots. Obtained balls occur when defensive players intersect passed balls, outbreak the ball and dead ball rebounds. Most of the college coaches think that winning 10-12 balls during first half is one of the important defensive goals (Trninić, 1996).

Blocks are events where a team shows individual or collective aggression in the phase of defence. It represents an indicator for evaluation of the central player in the phase of defence.

Table 1. Abbreviations and descriptions of each situational parameter

\begin{tabular}{|c|c|}
\hline Abbreviation & Description \\
\hline 2P-M & 2 points-made \\
\hline 2P-F & 2 points-fail \\
\hline 3P-M & 3 points-made \\
\hline 3P-F & 3 points-fail \\
\hline FT-M & Free throws-made \\
\hline FT-F & Free throws-fail \\
\hline RB-O & Offensive rebounds \\
\hline RB-D & Defensive rebounds \\
\hline AS & Assists \\
\hline PF & Personal fouls \\
\hline TO & Turnovers \\
\hline ST & Steals \\
\hline BS & Block Shots \\
\hline & \\
\hline & \\
\hline
\end{tabular}

Data analysis. For all parameters, arithmetic mean and standard deviation were calculated Kolmogorov-Smirnov test was used to determine whether the variables were normally distributed (maxD and $p$ value). Group differences between variables were analysed using multivariate analysis of variance (MANOVA) and Student's $t$-test for separate numerical differences. To determine parameters which differentiated teams according to outcome, discriminant analysis was performed. 


\section{RESULTS}

Statistical data of situational efficiency parameters of successful and unsuccessful male basketball teams. Results in Table 2 showed descriptive parameters of analysed situational variables. Also, asterisk $(*)$ represented statistical the difference between the teams according to outcome (win/lose). Table 3 represented results from multivariate analysis of variance in overall effect of each winning and defeated teams.

Table 2. Basic descriptive parameters of successful and unsuccessful male basketball teams

\begin{tabular}{|c|c|c|c|c|c|c|c|}
\hline \multirow{2}{*}{$\begin{array}{c}\text { Variables/Descriptive } \\
\text { parameters }\end{array}$} & \multirow{2}{*}{$\boldsymbol{N}$} & \multicolumn{2}{|c|}{ Mean \pm SD } & \multicolumn{2}{|c|}{ maxD } & \multicolumn{2}{c|}{$p$-value } \\
\cline { 3 - 8 } & & Winning & Defeated & Winning & Defeated & Winning & Defeated \\
\hline 2P-M & 38 & $22.84 \pm 4.37^{*}$ & $20.05 \pm 4.60$ & 0.11 & 0.14 & $>.20$ & $>.20$ \\
\hline 2P-F & 38 & $19.82 \pm 5.39^{*}$ & $23.34 \pm 4.46$ & 0.15 & 0.09 & $>.20$ & $>.20$ \\
\hline 3P-M & 38 & $9.32 \pm 5.50^{*}$ & $6.45 \pm 2.68$ & 0.17 & 0.13 & $>.20$ & $>.20$ \\
\hline 3P-F & 38 & $15.08 \pm 4.78$ & $13.74 \pm 4.30$ & 0.11 & 0.10 & $>.20$ & $>.20$ \\
\hline FT-M & 38 & $15.00 \pm 5.04$ & $12.82 \pm 5.58$ & 0.10 & 0.13 & $>.20$ & $>.20$ \\
\hline FT-F & 38 & $6.21 \pm 3.60$ & $5.82 \pm 3.14$ & 0.10 & 0.14 & $>.20$ & $>.20$ \\
\hline RB-O & 38 & $12.05 \pm 4.30$ & $10.37 \pm 4.43$ & 0.14 & 0.19 & $>.20$ & $<.15$ \\
\hline RB-D & 38 & $28.32 \pm 4.46^{*}$ & $25.21 \pm 4.59$ & 0.09 & 0.09 & $>.20$ & $>.20$ \\
\hline AS & 38 & $20.47 \pm 6.26^{*}$ & $13.87 \pm 4.91$ & 0.09 & 0.14 & $>.20$ & $>.20$ \\
\hline PF & 38 & $20.26 \pm 4.05$ & $21.08 \pm 4.96$ & 0.13 & 0.10 & $>.20$ & $>.20$ \\
\hline TO & 38 & $11.87 \pm 3.41^{*}$ & $15.11 \pm 4.26$ & 0.10 & 0.11 & $>.20$ & $>.20$ \\
\hline ST & 38 & $7.29 \pm 3.46^{*}$ & $4.55 \pm 2.68$ & 0.14 & 0.21 & $>.20$ & $<.10$ \\
\hline BS & 38 & $3.63 \pm 1.91^{*}$ & $2.50 \pm 2.10$ & 0.18 & 0.22 & $<.20$ & $<.05$ \\
\hline
\end{tabular}

Note. $*-p<.05$.

Presenting shooting results, successful teams scored $53.25 \%$ of 2 points-made, in contrast to unsuccessful teams $(46.75 \%)$. Opposed to successful 2 points-made, unsuccessful teams made more 2 points-fail $(52.87 \%$ vs. $47.13 \%)$. Successful teams scored $59.10 \%$ of successful 3 points-made, opposed to $40.90 \%$ scored by unsuccessful teams. In variable 3 points-fail, successful teams performed higher percentage $(52.32 \%)$ better than unsuccessful teams (47.67\%). Results from free throws-made showed higher percentage of realization by successful teams $(53.93 \%)$ contrary to unsuccessful ones $(46.07 \%)$, while similar percentages were obtained in free throws-fail among successful (51.64\%) opposed to unsuccessful (48.36\%) teams. Successful teams did more offensive $(53.75 \%$ vs. $46.25 \%$ ) and defensive rebounds $(52.90 \%$ vs. $47.10 \%)$. Also, winning teams performed better in assists $(59.61 \%)$, steals
(61.55\%) and blocks (59.23\%), but lower in personal fouls (49.01\%) and turnovers (44\%).

Multivariate analysis of variance between successful and unsuccessful male basketball teams in situational efficiency parameters. The aim of this part of study was to determine multivariate differences between successful and unsuccessful male basketball teams playing in the Olympic Games in London 2012 in a group of situational parameters. Results from table 3 showed that in general successful and unsuccessful teams statistically differed in situational indicators.

Table 3. Multivariate analysis of variance between successful and unsuccessful male basketball players

\begin{tabular}{|c|c|c|c|}
\hline Effect & Value & $\boldsymbol{F}$ & $\mathbf{p}$ \\
\hline Win/lose & 0.39 & 7.85 & $\mathbf{. 0 0}$ \\
\hline
\end{tabular}

Note. $p<.05$. 
Discriminant analysis between successful and unsuccessful male basketball teams in situational efficiency parameters. Further analysis in Table 4 represented discriminant differences across groups in situational efficiency parameters. Coefficients that statistically differentiated successful from unsuccessful teams were highlighted and marked with an asterisk.

\begin{tabular}{|c|c|c|c|}
\hline Variables & F-value & $\begin{array}{c}\text { Standardized } \\
\text { canonical coefficients }\end{array}$ & $\begin{array}{c}\text { Factor structure- } \\
\text { root 1 }\end{array}$ \\
\hline $\mathbf{2 P - M}$ & 0.40 & 0.123 & 0.311 \\
\hline $\mathbf{2 P - F}$ & 14.82 & $\mathbf{- 0 . 9 6 7 * *}$ & -0.076 \\
\hline $\mathbf{3 P - M}$ & 0.57 & 0.025 & 0.319 \\
\hline $\mathbf{3 P - F}$ & 5.57 & $\mathbf{- 0 . 4 0 3 *}$ & 0.202 \\
\hline FT-M & 0.40 & 0.228 & 0.236 \\
\hline FT-F & 0.09 & -0.007 & 0.110 \\
\hline RB-O & 16.38 & $\mathbf{0 . 9 4 3 * *}$ & 0.226 \\
\hline RB-D & 6.66 & $\mathbf{0 . 8 2 2} *$ & 0.320 \\
\hline AS & 0.22 & 0.123 & 0.516 \\
\hline PF & 1.18 & -0.232 & 0.077 \\
\hline TO & 14.03 & $-\mathbf{0 . 6 0 8 * *}$ & -0.147 \\
\hline ST & 4.78 & $\mathbf{0 . 4 2 5 *}$ & 0.407 \\
\hline BS & 3.16 & 0.449 & 0.275 \\
\hline
\end{tabular}

Table 4. Discriminant differences between successful and unsuccessful male basketball teams in situational efficiency parameters

\section{DISCUSSION}

The aim of the study was to determine a group of significant situational parameters that differentiated winning and defeated male basketball teams playing in the Olympic Games in London 2012.

Numerical values in Table 2 showed that statistical differences between successful and unsuccessful basketball were established in shooting variables, defensive rebounds, assists, turnovers, steals and blocks $(p<.05)$.

Global differences were identified between both successful and unsuccessful male basketball teams $(F$-value $=7.85 ; p=.00)$.

Partial differences occurred in variables 2 ptsfail $(F$-value $=14.82, \mathrm{SCC}=-0.967, p<.001)$, 3 pts-fail $(F$-value $=.57, \mathrm{SCC}=-0.403, p<.05)$, offensive rebounds $(F$-value $=16.38, \mathrm{SCC}=0.943$, $p<.001)$, defensive rebounds $(F$-value $=6.66$, $\mathrm{SCC}=0.822, p<.05)$, turnovers $(F$-value $=14.03$, $\mathrm{SCC}=-0.608, p<.001)$ and steals $(F$-value $=4.78$, $\mathrm{SCC}=0.425, p<.05)$.

According to presented results, the biggest positive contribution on the efficiency in the game was made by offensive rebounds (0.94). This result came from the fact that successful teams had greater percentage $(53.75 \%)$ of them than unsuccessful teams (46.25\%), along with greater unsuccessful shooting percentage among unsuccessful teams (successful teams $47.13 \%$ vs. unsuccessful teams $52.87 \%$ ). Nevertheless, aggressive offensive rebounds in the phase of attack represented a significant indicator for successfulness. According to Trninić et al. (1997), offensive rebounds were defined as extension of aggression of attack that opened the option of greater shoot percentage. This meant that the team had to close the way towards the basket. In that way, the team who got in possession of the ball had bigger percentage of shots and more successful transition from the phase of attack to defence, and vice versa.

Along with offensive rebounds, defensive rebounds contributed the most on the efficiency in the game (0.822). Trninić et al. (1997) explained that by maintaining the pressure on the ball in the phase of defence, stopping the opponents to achieve regular entrance in transitional and set offense along with stopping the attack with more than one shot. Successful teams forced unsuccessful teams for higher number of unsuccessful shots from the game and created greater chance for defensive rebounds (successful teams $52.90 \%$ vs. unsuccessful teams $47.10 \%$ ).

Steals, as one of the situational indicators, also showed significant contribution on the final result (0.425). Successful teams had higher percentage of successful steals $(61.55 \%$ vs. unsuccessful teams $38.45 \%$ ) opposed to unsuccessful teams, which could be explained by more aggressive play in defence, making pressure on a player with the 
ball and inaccurate passing the ball, which led to stealing the ball and made the fast transition from the phase of defence to the phase of attack.

Negative poles were obtained in variables 2 points-fail, 3 points-fail and turnovers. Variable 2 points-fail (-0.967) showed the biggest difference between successful and unsuccessful teams. Successful teams scored fewer unsuccessful shots for 2 (47.13\%) opposed to unsuccessful teams (52.87\%). Successful teams sent more shots from favourable positions; they had better shot selection and greater number of shots from the zone of high percentage of shots. It was also assumed that defence of successful teams was successfully prevented by regular entrance and line movement of the unsuccessful players in transitional and set attack.

Along with 2 points-fail, 3 points-fail represented lower, but also significant contributor of discrimination of successful teams from the unsuccessful ones (-0.403). Successful teams performed higher percentage of 3 points-fail (52.32\%) than unsuccessful teams (47.67\%). Nevertheless, successful teams compensated that with more 3 points-made (9.32 vs. 6.45), where they had "clearer" chances and open shots to score the shot.

Last negative variable that discriminated successful from unsuccessful teams was turnovers $(-0.608)$. Successful teams performed lower in turnovers (44\%) vs. unsuccessful teams $(56 \%)$. This could be explained by lower technical-tactical preparedness in unsuccessful teams where players did not have game conversation on the optimal level. Cooperation between two or more players in unsuccessful teams failed because of bigger pressure and aggression of the players playing defence in successful teams.

Previous results from Pojskić et al. (2009) showed similar results, where assists, percentage of 2 points scored, 2 points-made, defensive rebounds and bench points were situational parameters that differentiated groups the most. The study conducted by Grgurević, Jelaska, and Jelaska (2014) showed that variables points-made, defensive rebounds, 3 point shots-total, free throws-total and fouls-made statistically differentiated the winning teams from the defeated ones.

Also, Sindik and Vidak (2010) showed that discriminant function did not indicate statistical significance among the players of the four most successful and 5 less successful teams based on all the standard situation efficacy parameters in basketball. Only two parameters, 2 points-made and 2 pointsfail, showed statistically significant differences between more and less successful teams.
Nakić (2004) showed the largest differences between successful and unsuccessful teams in free throws, assists, 2 points-fail and 3 points fail. The author explained the results by basketball games not being as elite as those played in European championships with the lack of motivation during the competition.

Trninić et al. (2002) presented results which were similar to the present study, where the highest discriminative power was obtained in the variable defensive rebounds, free throws-total, field goaltotal and assists.

Results from our study were also supported with results by Gomez et al. (2008), where winning teams showed better defensive performance. The authors concluded that good defence avoided the opponents' assists and forced poor shots. In unbalanced game, differences between winning and losing teams were in defensive rebounds and the games ended unbalanced by the differences in successful 3 point field-goals (Garcia et al., 2013).

Based on the obtained results in the study, model game of successful teams was based on strict selection of a 2- and 3-point shots from the external positions, as many offensive rebounds (to start new attack in the game) along with defensive rebounds (try to win the ball in defence with fast transitions in the phase of attack). Also, assists with stolen balls speed the game up and player's creativity came to higher level of performance. All these indicators comprised technical and tactical actions in the phase of attack and defence where players had to be well-prepared for the upcoming competition during the specific cycle period.

\section{CONCLUSION}

In conclusion, our results indicate that winning and defeated male basketball teams playing in the Olympic Games differed in situational efficiency parameters. Obtained in all studies, defensive rebounds were on the highest level of discrimination between successful and unsuccessful teams, also, with 2- and 3-points shots-fail, offensive rebounds, turnovers and assists. Based on the obtained results, coaches need to pay more attention to the team's transition from attack phase to defence and vice versa. Basketball game consists of very complex technical-tactical structures, which are required to gain advance over the opponent. Only using those elements on high level, teams can achieve positive outcome, especially in offensive and defensive rebounds, like it was shown in our and other studies. 


\section{REFERENCES}

Akers, M. D., Wolff, S., \& Buttress, T. (1991). An empirical examination of the factors affecting the success of NCAA Division I College Basketball teams. Journal of Business and Economic Studies, 1, 57-71.

Dezman B., Erculj F., \& Vuckovic, G. (2002). Differences between winning and losing teams in playing efficiency. Acta Kinesiologiae Universitatis Tartuensis, 7, 71-74.

Gabbett, T. J. (2008). Influence of fatigue on tackling technique in rugby league players. Journal of Strength and Conditioning Research, 22(2), 625-632. doi: 10.1519/JSC.0b013e3181635a6a

García, J., Ibáñez, S. J., De Santos, R. M., Leite, N., \& Sampaio, J. (2013). Identifying basketball performance indicators in regular season and playoff games. Journal of Human Kinetics, 36, 161-168. http://doi.org/10.2478/ hukin-2013-0016

Gómez, M. A., Lorenzo, A., Ortega, E., Sampaio, J., \& Ibáñez, S. J. (2009). Game related statistics discriminating between starters and nonstarters players in Women's National Basketball Association League (WNBA). Journal of Sports Science and Medicine, 8, 278-283.

Gómez, M. A., Lorenzo, A., Sampaio, J., Ibáñez, S. J., \& Ortega, E. (2008). Game-related statistics that discriminated winning and losing teams from the Spanish men's professional basketball teams. Collegium Antropologicum, 32(2), 315-319.

Grgurević, A., Jelaska, I., \& Jelaska, P. M. (2014). Differences between successful and unsuccessful teams in indicators of situational efficiency in basketballcase of elite clubs. In S. Pantelić (Ed.), XVII Scientific Conference "FIS COMMUNICATIONS 2014" in physical education, sport and recreation and II International Scientific Conference. Serbia, Niš: Faculty of Sport and Physical Education, University of Niš.

Gruić, I., Vuleta, D., \& Milanović, D. (2006). Performance indicators of teams at the 2003 Men's World Handball Championship in Portugal. Kinesiology, 38(2), 164-175.

Hunter, P., \& O'Donoghue, P. (2001). A match analysis of the 1999 Rugby Union World Cup. In M. D. Hughes, I. Franks (Eds.), Book of abstracts Fifth World Congress of performance analysis in sports (pp. 85-90). Cardiff: UWIC.

Ibáñez, S. J., Sampaio, J., Feu, S., Lorenzo, A., Gómez, M. A., \& Ortega, E. (2008). Basketball game-related statistics that discriminate between teams' season-long success. European Journal of Sport Science, 8(6), 1-4.

Knight, B., \& Newell, P. (1986). Basketball (Vol 1). Seamoor: Graessle Mercer Co.

Melnick, M. J. (2001). Relationship between team assists and win-loss record in the National Basketball Association. Perceptual and Motor Skills, 92, 595-602.
Milanović, D. (1978). Effects of ball shooting variables in the basket on final score of basketball game. Kinesiology, 9(1-2), 135-149.

Montgomery, P., Pyne, D., Hopkins, W., Dorman, J., Cook, K., \& Minahan, C. (2008). The effect of recovery strategies on physical performance and cumulative fatigue in competitive basketball. Journal of Sports Sciences, 26(11), 1135-1145.

Nakić, J. (2004). Differences in standard and derived situation efficacy parameters between men's and women's basketball teams in senior European basketball championships in 2003 (Unpublished master thesis). Zagreb: Faculty of Kinesiology.

Pojskić, H., Šeparović, V., \& Užičanin, E. (2009). Differences between successful and unsuccessful basketball teams on the final Olympic tournament. Acta Kinesiologica, 3(2), 110-114.

Royal, K. A., Farrow, D., Mujika, I., Halson, S. L., Pyne, D., \& Abernethy, B. (2006.) The effects of fatigue on decision making and shooting skill performance in water polo players. Journal of Sports Sciences, 24(8), 807-815.

Sampaio, J., \& Janeira, M. (2003). Statistical analyses of basketball team performance: Understanding team's wins and losses according to a different index of ball possessions. International Journal of Performance Analysis in Sport, 3, 40-49.

Sindik, J., \& Vidak, N. (2010). The difference between top senior basketball players from differently ranked teams in terms of situation efficacy parameters. Facta Universitas. Series: Physical Education and Sport, 8(2), 163-171.

Swalgin, K. (1994). The basketball evaluation system: A scientific approach to player evaluation. In J. Krausse (Ed.), Coaching basketball (pp. 40-43). Indianapolis: Master Press.

Trninić, S., Dizdar, D., \& Dežman, B. (2000). Empirical verification of the weighted system of criteria for the elite basketball players quality evaluation. Collegium Antropologicum, 24(2), 443-465.

Trninić, S., Dizdar, D., \& Lukšić, E. (2002). Differences between winning and defeated top quality basketball teams in final tournaments of European club championship. Collegium Antropologicum, 26(2), 521-531.

Trninić, S., Milanović, D., \& Dizdar, D. (1997). Discriminative analysis of successful and unsuccessful teams in space of standard indicators of situational efficiency in basketball game. Leistungs Sport, 2, 29-34. Trninić, S. (1975). Relations between frequencies of defensive and offensive rebounds and final result in basketball games (Master thesis). Zagreb: Faculty of Physical Education.

Trninić, S. (1996). The analysis and learning of basketball game. Pula: VIKTA d.o.o 